\title{
Beyond the Vampire: Revamping Thai Monsters for the Urban Age
}

\author{
Katarzyna Ancuta \\ King Mongkut's Institute of Technology Ladkrabang, Thailand
}

\begin{abstract}
This article revisits two of the most iconic Thai monstrosities, phi pop and phi krasue, whose changing representation owes equally as much to local folklore, as to their ongoing reinterpretations in popular culture texts, particularly in film and television. The paper discusses two such considerations, Paul Spurrier's $P(2005)$ and Yuthlert Sippapak's Krasue Valentine (2006), films that reject the long-standing notion that animistic creatures belong in the countryside and portray phi pop and phi krasue's adaptation to city life. Though commonplace, animistic beliefs and practices have been deemed incompatible with the dominant discourses of modernization and urbanization that characterise twenty-first century Thailand. Creatures like phi pop and phi krasue have been branded as uncivilised superstition and ridiculed through their unflattering portrayals in oddball comedies. This article argues that by inviting these monsters to relocate to contemporary Bangkok, Spurrier and Sippapak redefine their attributes for the modern urban setting and create hybrids by blending local beliefs and cinematic conventions. The creatures' predatory character is additionally augmented by the portrayal of the city as itself vampiric. The article therefore reads these predatory spirits in parallel with the metaphor of the female vampire - a sexually aggressive voracious creature that threatens male patriarchal order and redefines motherhood.
\end{abstract}

Keywords: phi pop, phi krasue, monsters, evil spirits, Thai horror film, the monstrous feminine

T $f$ we define the vampire as an undead revenant sustained by consuming (preferably 1 human) blood, then it is safe to say there are no vampires in Thailand. This does not mean, however, that Thai monster ${ }^{1}$ lore is free of beings that could be called "vampiric", in a sense that they need to feed off humans to survive. The two most culturally widespread examples include phi pop and phi krasue, creatures with an appetite for viscera and abject

\footnotetext{
${ }^{1}$ The term "monster" is used rather loosely in the paper to refer to a corporeal creature that inspires fear. In the words of Judith Halberstam: "The monster functions as monster [...] when it is able to condense as many fear-producing traits as possible into one body" (1995, p. 22). Since both phi pop and phi krasue can be at the same spiritual and corporeal creatures, they are simultaneously spirits and monsters.
} 
bodily discharges like menstrual blood, placenta, or excrement. For foreign scholars, phi pop and phi krasue are notoriously difficult to describe. They certainly defy Western terminology of ghosts, spirits, monsters and demons, but at the same time, exhibit features characteristic of all the above. They complicate our understanding of the supernatural, since while they could easily be described as extraordinary or superhuman, in animistic Thailand, they are considered very much part of the natural world. And given the fact that they are also commonly perceived as real, it is not always possible to call them fantastic or imaginary. ${ }^{2}$ For the sake of clarity, this paper proposes to read phi pop and phi krasue as vampiric (but not vampires), while noting that their "undead" (i.e. immortal) status is achieved through a type of spiritual/demonic possession (voluntary or involuntary), rather than reanimating the dead. Both phi pop and phi krasue are known to enter the living body of a host, predominantly a woman who dabbled in black magic, inherited the "curse" from her ancestors, or became infected by swallowing another creature's saliva, and reconstitute this body for its purposes. This is spectacularly visible in the case of phi krasue as the creature suffers nightly separations of the head from the body, where the head then flies away into the night in search of food, drawing a bloody trail of its entrails behind it. The term phi pop or phi krasue is therefore used indiscriminately to refer to the spirit, its human carrier, and any intermediate forms it assumes.

Anthropological accounts of phi pop and phi krasue are full of contradictions, their precise classification practically impossible, since they are known by several overlapping names in different regions of Thailand and their characteristics merge with those of other $p h i^{3}{ }^{3}$ They are both commonly identified as "evil spirits" a person gets possessed by, or turns into, as punishment for "the breaking of taboos associated with malevolent forms of magic" (Baumann, 2016, p. 154). They are often thought to be hereditary: phi krasue can only die after she convinces a female relative "to eat some of her spittle" (Irwin, 1907, p. 25) and become krasue in her place, and phi pop moves on to inhabit the children (from father to son, from mother to daughter) after its original host dies of old age (Suwanlert, 1976a, p. 69). Phi pop can additionally originate in auspicious objects, from which they transfer to humans (p. 69). At the same time, since they are mostly seen in their corporeal form, they are also perceived as monsters in addition to spirits. An amalgamation of human and spirit, phi pop and phi krasue are inherently dualistic creatures - the term referencing simultaneously the spiritual/demonic entity and its host - a confusing combination of a victim, container, and a masterful witch. Phi pop and phi krasue tend to live as humans by day (again it is debatable whether they are humans containing the spirit within or spirits masquerading as humans) and engage in supernatural activities by night, at which point they are often thought to be separate from their hosts, although somehow retaining their material form. They are also predominantly gendered beings - phi krasue is always female, appearing "as an old ugly woman, a beautiful young maiden or ordinary village girl" (Baumann, 2014, p. 184), and though phi pop is often thought to be shapeless and can possess men and women alike, its most memorable representations

\footnotetext{
${ }^{2}$ While it may be tempting to compare phi pop and phi krasue to similar Southeast Asian beings, it would be difficult to treat them as equivalent. Phi krasue, for instance, may share many characteristics with the Filipino manananggal, Malay penanggalan, or Indonesian leak but they are certainly not the same. Such comparisons are also of limited use when describing these creatures in English.

${ }^{3}$ Most commonly translated as "spirits," the Thai word phi can also refer to ghosts (i.e. dead humans), demons (i.e. evil immaterial spirits), or monsters (corporeal creatures).
} 
are similarly female, perhaps because women are said to be uniquely predisposed to being invaded by spirits due to their weak or disorganised khwan - vital essence (Kirsch, 1977, pp. 258-259)

While phi pop often mimics its host and phi krasue hunts in a semi-complete form of a detached head with entrails, both entities are also capable of entering their victim's body and feeding on its organs from within, causing illness and death. They are characterised by their voracious appetite (usually for things raw and disgusting to humans) and the inability to stop themselves from eating, which is why they end up consuming people even though they prefer to stay away from them to avoid detection. Although usually feasting on "faeces $(k h i)$, carrion and livestock" (Baumann, 2016, p. 155), attracted by the smell of blood, phi krasue is thought to be particularly dangerous to women in childbirth, entering their bodies to eat the entrails of the baby and thus causing stillbirth. Afterwards, she continues to feed on the innards of the mother, causing her waste away with illness until she dies (Rajathon, 1954, p. 158). Phi pop's consumption of its host from within similarly manifests itself as physical or mental illness. Suwanlert compared the symptoms of possession to a dissociative disorder and diagnosed it as hysterical neurosis (1976b, p. 21). Phi pop is also said to be able to temporarily leave the body of its host and possess another (p. 21), just as it can be sent out with a deliberate intention to harm others (Irwin, 1907, p. 13). While the originating hosts are usually driven away to live in exile, phi pop can sometimes be exorcised by incantations or, more drastically, beaten out of the afflicted person with a magic rod, after which the person continues to live a regular life (Rajathon, 1954, p. 164).

Like many Thai animistic beings, phi pop and phi krasue have traditionally been associated with the wilderness, from which they moved into the bordering villages to live among humans. As the villagers began to migrate to Bangkok for work, so did their monsters, though they did not get much of a welcome in the city. Although individual beliefs prevailed, animistic practices were officially rejected as "uncivilised" relics of the barbaric past incompatible with the dominant discourses of modernization and urbanization. Creatures like phi pop or phi krasue were deemed incapable of change and urban adaptation. This is not to say that Bangkok did not have its dark side. Like any metropolis with growing potential for accidents and crime, it was quickly filling up with vengeful spirits of the violently dead. Unable to compete as the figures of fear, upon entering the city many animistic beings embraced the spirit of capitalism instead, giving rise to a series of prosperity cults where they got busy securing lucrative business contracts, disclosing lucky lottery numbers, and helping people make money in exchange for offerings and veneration. This polarisation was reflected in popular media like film and television, which began to feature indigenous Thai spirits/monsters in oddball comedies set in the backward countryside, in contrast with more serious globalised urban vengeful ghost stories that felt more "appropriate" for Bangkok. Recently, however, we have witnessed the appearance of new hybrid monstrosities redefining the seemingly unchangeable Thai animistic beings and reframing them in modern urban settings. This paper discusses two such cases, Paul Spurrier's film $P$ (2005), and Yuthlert Sippapak's Krasue Valentine (2006), which portray phi pop and phi krasue's adaptation to city life. The article argues that the urban versions of these monsters are hybrids blending local beliefs and 
cinematic conventions, and that their predatory character is augmented by the portrayal of the city as itself vampiric.

\section{"I won't eat you from the inside": Phi pop as a sex worker in $P$}

Do you know what I do? I enter your body and I work my way through. I eat your kidneys, the liver, the spleen, the heart, the lungs. But I'm not going to do that to you. I won't eat you from the inside. I'm going to eat you from the outside! It'll be just as tasty $(P, 2005)$.

The film's protagonist, Dau (initially Aaw) is a girl from Si Saket province in Lower Isan. She is a lonely child, ostracized by others. Dau lives at the edge of the village with her spooky grandmother, who is proud to identify as Khmer, since they "know things not many Thai people know." The "things" in question are the reference to (black) magic the Khmer are commonly associated with in Thailand. Khmer magic is believed to be especially potent, it is also perhaps the most unnerving, as the ingredients used in its rituals often include "the mixing of abjected bodily substances, like menstrual blood, excrements and corpse remnants, with sacred knowledge" (Baumann 2016, p. 163). As a descendant of a witch, Dau learns magic, the practice of which comes with three restrictions: she is not allowed to eat raw meat, pass under a clothesline, or take any payment for teaching others. If she breaks these rules, she risks her body being taken over by an evil spirit, which the director, Paul Spurrier identifies as phi pop: the spirit that enters your body and gradually drives you crazy with a yearning for innards, offal and all manner of viscera. If you see someone in Thailand eating raw meat - 'larb dip' [lap dip] - rather more often than usual, you should watch out! Before long their craving will grow, until soon they can change their form and enter your body through any orifice and then proceed to eat you from the inside. The 'phii bawb' [phi pop] is the particular ghoul that I chose for ' $P$ ' (Brown, 2005, 4, para. 14).

Given the creature's description, locality, and Khmer origin, Baumann, however, argues that the being described in the film, the Lower Northeastern variation of phi pop, is in fact a blend of the Northeastern phi pop and Central Thai phi krasue, known to regional Khmer-speakers as phi thamop. In Lower Northeastern Thailand, these three terms are often used interchangeably to refer to the same creature that signifies a witch-like phi (2016, p. 154), while in other regions phi krasue, phi pop and phi thamop are distinct beings with unique characteristics. ${ }^{4}$

Regardless of its folklore characteristics and the prevailing belief that even in today's Thailand phi pop can be encountered in "real life," the image of the creature constructed in the film is to a large extent vampiric. Its hybrid nature reflects the fact that "[i]n an era of global capital, filmmaking often must negotiate between the culturally nomadic and the culturally specific" (Hudson, 2010, p. 206). This comes as no surprise, seeing as the entire film is very much a cultural hybrid. Directed by a British director living in Thailand, the film was widely advertised

\footnotetext{
${ }^{4}$ Most of the anthropological texts related to phi pop describe the Northeastern Thai phi pop, while most accounts of phi krasue focus on Central Thai phi krasue. This does not mean that these terms are unknown in other regions of Thailand, however, they are frequently associated with a different set of features.
} 
as "the first Thai [and Thai-language] film made by a westerner." The portrayal of the spirit/monster therefore owes equally much to Thai ghostlore, as to the cinematic conventions used to portray the monstrous-feminine in horror films. In the film, the creature is shown to leave Dau's body and hunt for food. While Dau stays in bed troubled by nightmares, her demonic doppelgänger goes on a rampage in another part of town. The monster's body is an array of signifiers (see Figure 1). The prominent fangs, shots showing its face in proximity of the victim's neck, and copious blood spillage represent the vampire. The bluish skin colour of the creature and her glowing golden eyes evoke the image of the Hindu goddess of destruction Kali, also a fanged being, but at the same time reference iconic representations of Thai ghosts in post-war 16-mm horror films. The CG shots of human organs in decay, touched by disease, reference the method of attack by phi pop and phi krasue. Then there is also a hint of an apsara, a Cambodian shape-shifting female divinity often represented in Khmer art and court dances (Baumann, 2014, p. 187), implied by Dau's Khmer origin, but also the costumes she wears when she dances on stage and the design of the bar incorporating crude renderings of Khmer carvings.

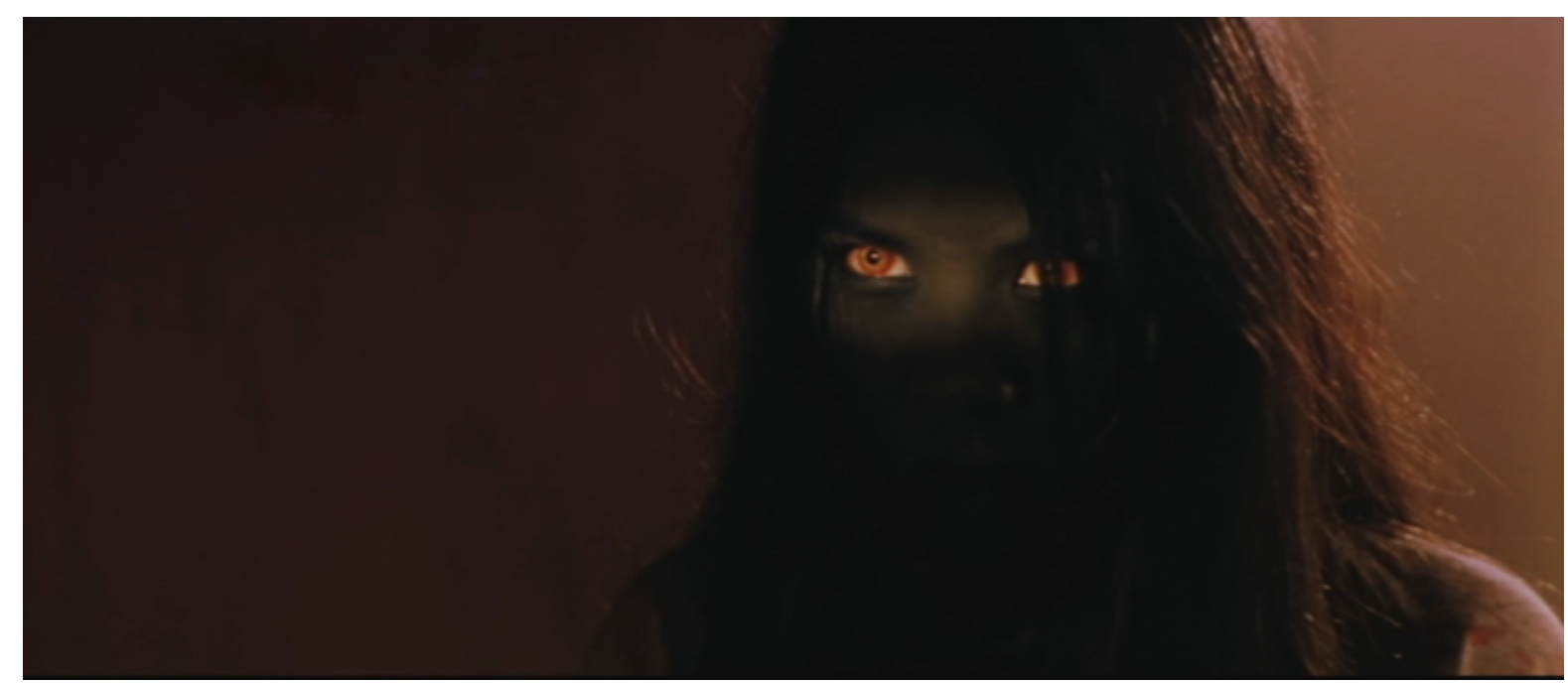

Figure 1. Dau in her incarnation as phi pop (Spurrier, $P, 2005)$

The being that Dau becomes, or contains within herself, is a complex combination of three common representations of the monstrous feminine, a category proposed by Barbara Creed to highlight "the importance of gender in the construction of her monstrosity" (1993, p. 3). She fits into Creed's categories of woman as "possessed monster," "vampire," and "witch." Each of these beings is a figure of abjection: demonic possession transgresses the boundary between the self and other (p. 32); the female vampire disrupts identity and order, but also blurs the difference between dead and alive, human and animal (p. 61); while the witch "sets out to unsettle boundaries between rational and irrational, symbolic and imaginary" (p. 76). Although Creed's model of the monstrous feminine can be criticised as Western-centric and promoting cultural conceptualisations of gender that may be incompatible with Southeast Asian realities, given the fact that in Thai patriarchal society women are expected to adhere to strict gender roles and their agency is most frequently curbed by exercising control over their sexuality, it is nevertheless relevant. As a product of Thai skewed gender and socioeconomic hierarchies which favour men over women, rich over poor, and Bangkok over the 
rest of the country, Dau is already potentially monstrous (and abject) because she is poor, she belongs to a marginalised ethnic group, and comes from an underdeveloped rural province. Her social class, material status and ethnicity delegate her to the "twilight zone," simultaneously invisible and threatening to the public image of a country focused on the urban middle classes. The fact that in Thai films, impoverished provinces are filled with monsters is not only a commentary on their supposed "backwardness", but also the result of the national mechanism of repression that chooses to ignore social problems like poverty or gender inequality in order to maintain an illusion of a modern prosperous society. ${ }^{5}$

Like many of her peers, Dau comes to Bangkok lured by the promise of making money. She works in a bar where she dances on stage, entertains foreign men, and sleeps with them for an extra price. The film depicts sex workers as dualistic creatures, much like phi pop. They are victims of circumstances: most of the girls come from impoverished provinces or Bangkok slums and have turned to prostitution for economic reasons; they are further abused by their criminal employers who profit from their work and keep them in debt; and they are also victims of gender/racial exploitation stereotyping Asian women as sexual playthings for white men. However, at the same time, the film does not dwell on their victimisation, but rather suggests that the work they do is at least to some extent their active choice. Dau's girlfriend, Pookie, explains that their work is all about performance, as she sleeps with men for money despite the fact that she identifies as a lesbian. She instructs Dau on how to manipulate their clients and take advantage of them, and how to choose only the ones who "can afford her." In this new environment where everybody is feeding off somebody else, Dau's monstrous transformation goes unnoticed. After her transition, she becomes just another "predatory bargirl" luring men to destruction, one more popular local creature demonised in foreigners' travel stories from Thailand. Interestingly, however, the migration to the vampiric city is equally transformative to Dau as it is to the phi pop which reinvents itself as a modern capitalist monster that feeds on its victims for profit.

The binary nature of female monstrosities who are both pitiful victims of male abuse and sexually aggressive predators is rather characteristic of Southeast Asian horror narratives. One such figure, the Malay pontianak, is identified by Andrew Hock Soon $\mathrm{Ng}$ as an amalgamation of ghost and vampire. As a ghost, she is a product and a melancholy reminder of the systemic violence against women (a woman redeemed, since in death her honour is restored), while as a vampire she is a dangerous rebel using her sexuality to threaten the masculine social order (a female monster that needs to be destroyed). $\mathrm{Ng}$ observes that "the vampire metaphor is utilized to comment on the schizophrenic identity of the Malay woman: her tussle between autonomy and dependence, agency and subservience finds an excessive expression through the potent, dangerous body of the vampire" (2010, p. 175). Although his analysis is specifically related to women in Islamic culture, much of this is true in the Buddhist context of Thailand, where patriarchy reigns supreme. In fact, it is the patriarchal positioning of women in Thai culture, which restricts their access to the official Buddhist order (marked as male) and describes them as more likely to interact with animistic beings, that has allowed

\footnotetext{
${ }^{5}$ The recent political upheaval and accompanying discourse on "uneducated low-class people" as a destabilising element threatening the current power status in the country demonstrates the fear of the rise of the discontented poor.
} 
women to gain authority as witches and spirit mediums (Ainslie, 2014, p. 162) and ironically made them more likely to turn into phi pop or phi krasue. Dau's lineage of sorcery, her profession as a sex worker, engagement with witchcraft, and transformation into a female vampiric monster simultaneously mark her as a "bad woman" and a threat to the dominant social order (see Figure 2).

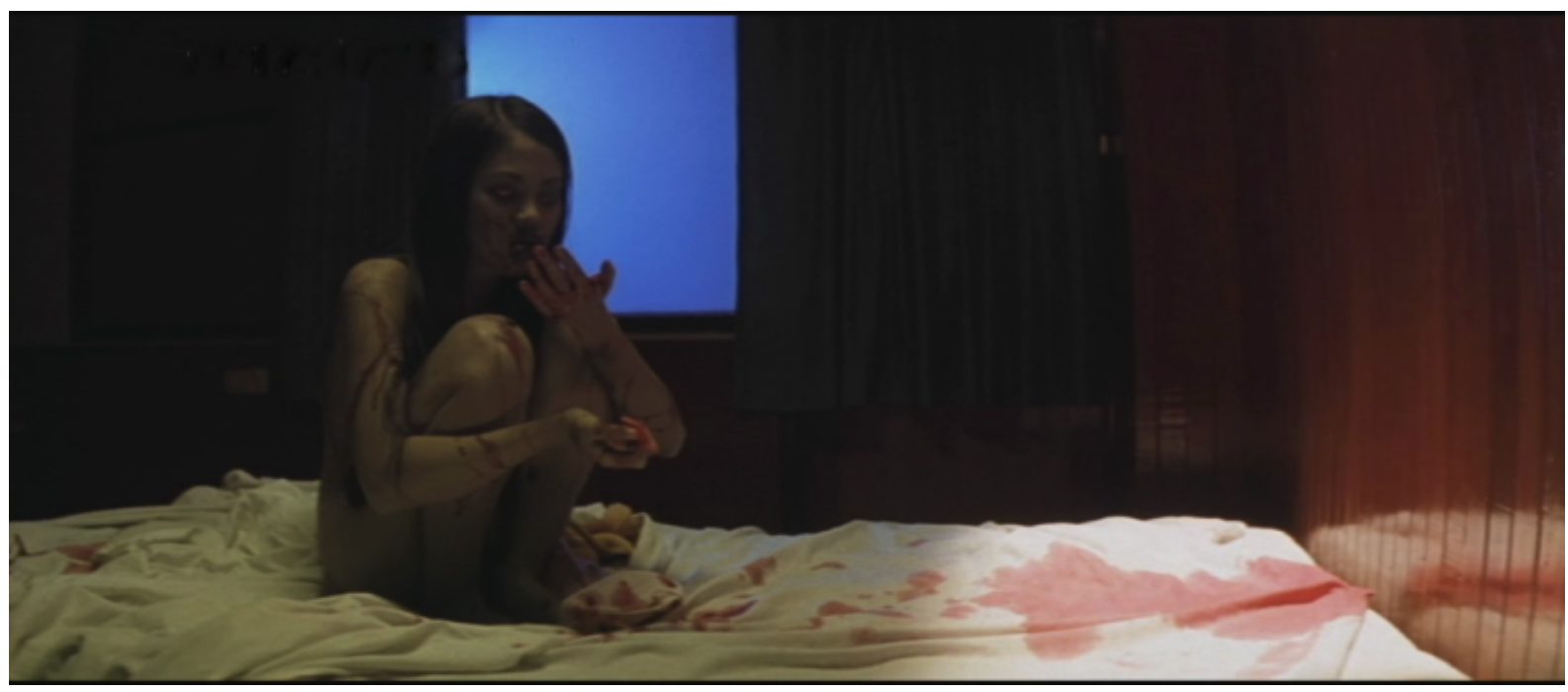

Figure 2. Dau-phi pop as a sexualised vampiric creature feeding on one of her customers (Spurrier, $P$, 2005)

Although the film's depictions of monstrous female sexuality (aggressive, voracious, manipulative, or lesbian) serve to "reinforce the phallocentric notion that female sexuality is abject" (Creed, 1993, p. 151), at the same time, "the notion of the monstrous-feminine challenges the view that femininity, by definition, constitutes passivity" (p. 151). This is particularly visible in the way the film portrays male impotence in this vampiric world of women. The shaman who attempts to exorcise the phi pop is defeated without much of a fight, his body forcibly penetrated from behind by the monster. The owner of the bar who initiated Dau into the vampiric sex business by forcing her to perform oral sex on him (contrasting "eating from the outside" with "eating from the inside") has his manhood devoured by a snake conjured by Dau's magic. The clients are treated instrumentally, as a source of income, or food for the monster. The film is brutal in its portrayal of sex tourists and sexpats as unattractive and not very intelligent. A shot of an old, flabby and extensively hairy foreigner on top of Dau is accompanied by the voiceover of her grandmother warning her about turning into an ugly and horrible creature. Minutes later, the same foreigner is eaten alive by Dau-phi pop in a reversed shower scene from Psycho (1960).

While the film ultimately portrays men as weak, it suggests that female evil must be defeated by a woman. The final challenge to the monster comes from a disfigured ex-dancer, Mai, who invites the demon to consume her and commits suicide in the process. She jumps off an overpass onto a busy road and ends up tossed onto a tree marked with colourful cloth to imply it contains a female tree spirit, nang mai. Since Mai died a violent death, it is likely that her ghost, phi tai hong, will move into the tree to share in the tree spirit's veneration. In Thai popular beliefs, nature spirits that are said to inhabit trees often blend with souls of the deceased, especially those who die unexpected violent deaths in the vicinity. This is 
particularly common in the urban context where trees frequently mark the sites of car crashes. Both the tree spirits and ghosts of the violently dead are thought to inhabit the tree and are subsequently plied with offerings by the living. However, the ending of the film does not offer closure. As we see Dau waking up from her dream we do not know whether the vampiric phi pop is still a part of her. Chances are it will come back because phi are eternal and they live on even if their hosts are long gone. Or perhaps the inclusion of the spirit tree in the scene was meant to signal that the battle would now be fought between the good and evil phi. The final shots of the film show Dau transformed from a shy virgin hiding behind a stage pole to a confident erotic dancer as she returns to the stage. She has caused the deaths of four of her co-workers and several clients, but she will always be welcome at the bar. Even if the voracious spirit has left her, she has already become a different type of vampire all of her own.

\section{"Do you say your prayers before going to sleep": Phi krasue as an impossible mother in Krasue Valentine}

Do you say your prayers before going to sleep? No, never. You should. It earns you a lot of merit...it will help you achieve redemption. [...] What you are suffering from cannot be cured by medicine. It can only be cured by merit. What am I suffering from? Karmic retribution (Krasue Valentine, 2006).

The film's heroine, Sao, owes her name to the first cinematic krasue portrayed in Krasue Sao (1973), as if reminding us that this condition is hereditary. Saowadee is a nurse who has come to seek employment at a small hospital in Bangkok. The hospital is old and practically empty, because patients have moved on to more modern facilities. It is also decrepit, since its director does not manage it properly. In fact, we learn he has gambled away all his money and the hospital with it. The property includes a derelict gym, rusting away since its key has been lost; a collection of overflowing dumpster bins; and a haunted house, which serves as Sao's bedroom. The hospital seems to have only one patient - a comatose Buddhist nun whose entire purpose in the film is to dispose spiritual wisdom through an out-of-body experience. The hospital's dysfunctional staff include a limping cleft-faced porter, an effeminate clownish night guard who sleeps on the job, and an old janitor who is a drunk. There is also a creepy little girl who appears out of nowhere to sell roses that nobody wants to buy.

Sao feels inexplicably drawn to the disabled porter, Num. She is certain that the two of them are connected, having found a faded photograph from 1941 of a couple that looks exactly like them. The photograph, accompanied by a love poem, seems to promise that Sao has finally found her soulmate. What Sao does not know, however, is that she is a krasue, something the audience becomes aware of very early in the film as Sao's floating head is seen rummaging through rubbish (see Figure 3). Phi krasue is a "filth ghost" attracted to blood, guts, and excrement; medical waste, therefore, must seem equivalent to a gourmet buffet. Although we do not see the krasue eat, in the morning Sao wakes up with blood on her face, indicating she has been drinking blood or devouring raw meat. She feels the urge to throw up, (pointing to indigestion or possibly hinting at pregnancy) and right after purging she fishes out

${ }^{6}$ Although technically not a ghost, phi krasue has often been translated as a "filth ghost." 
her vomit from the toilet bowl, producing a length of blood-soaked intestines, or perhaps an umbilical cord. This is exactly what Baumann recognises as sok prok-impurity, filth, or "matter out of place," the fondness of which identifies phi krasue as a creature of the abject (2016, p. 154).

Despite her striking looks and peculiar diet, the krasue depicted in the film has little in common with the creature studied by anthropologists. Although Sao came to Bangkok from Aranyaprathet (a border town with Cambodia), hinting at the Khmer connection that Baumann claims fits in with the origin myth of phi krasue, this is never fully explored and the creature's mythology is changed. The film merges her krasue characteristics with those of a ghost, explaining her fate as linked to karmic retribution. People who accumulate too much bad karma, we are told by one of the characters in the film, are expected to pay the karmic debt over subsequent reincarnations. They sometimes "reincarnate into ghosts and demons" and remain trapped in this state until they improve their condition through merit. Thai horror films often turn to ghost stories to illustrate the concept of karmic retribution, although the typical convention is to portray the ghost as a vengeful soul that does not want to relinquish its grudge and thus clings to its own suffering. A classic example of such representation could be the spirit of Natre from Shutter (2004) perched on the shoulders of the man who betrayed her in the final scene of the film. She has avenged her pain and destroyed his life, but she has done so at the cost of her own redemption. The ghostly return of Sao, however, is not motivated by vengeance - at least not her own.

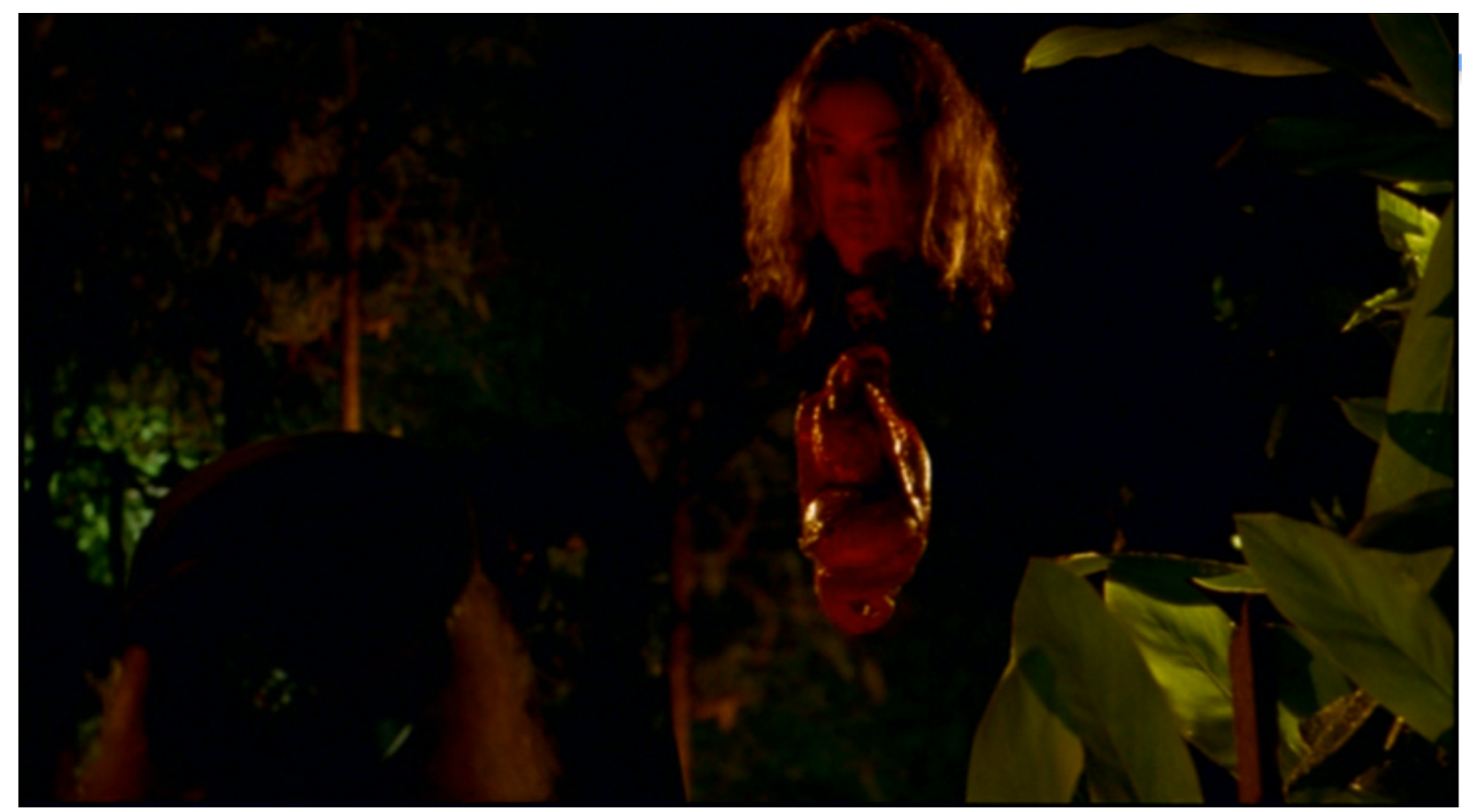

Figure 3. Sao haunting the hospital grounds in her phi krasue form (Sippapak, Krasue Valentine, 2006)

Sao, Num, and the director of the hospital, are trapped in a karmic circle of repetition destined to face responsibility for their mistakes and meet a tragic end. Their previous lives were set in 1941. Back then, Num was a soldier recovering from a minor injury at the same hospital. Sao and Num began dating. When Num left the hospital he promised to return for her, but then chose to marry another woman to ensure his promotion instead. Sao found out she was 
pregnant. Distressed and alone, she aborted the baby. The director of the hospital was the doctor who prescribed the abortion pills. All the three characters bear signs of bad karma: Num is disabled, the director is a gambling addict, and Sao is phi krasue. In the course of the film they additionally fall victims of the vengeful ghost of the aborted baby, which manifests itself as a flower-selling girl or an old skinny man. This age/gender disparity suggests that perhaps this is not the first time that Sao, Num and the director have been made to suffer for their sins. In fact, one of the nurses mentions a female doctor who previously killed herself in Sao's room, perhaps bearing connection to the story. In the end, Num is strangled by his ghost-child and becomes a ghost himself, the director dies of an acute allergic reaction to a field of roses magically growing inside the derelict gym, and Sao gets trapped forever in her krasue form, her body destroyed in a fire. The hospital, sold to a new owner, is about to get a makeover, but it does not look like it is going to be free of its past.

Like Dau in $P$, Sao is clearly a hybrid: part ghost, part krasue, part human. The film director, Yuthlert Sippapak is known for his genre-blending approach to filmmaking, in this case a mixture of horror, comedy and romance. The ghost side of Sao triggers our empathy, as we wonder whether her punishment is not too severe. It also vindicates the character to a certain extent, as the first Sao's abortion and potential suicide are at least partially blamed on men her lover who refused to take responsibility for the affair and the doctor who convinced her to get rid of the baby. The krasue element in the film is an excuse to showcase oddball characters who serve as comic relief as they aimlessly chase after the monster. This is rather typical of Thai cinema, where phi krasue is commonly a source of ridicule and ghosts are simultaneously scary and pitiful. At the same time, the very few attributes of phi krasue the film has retained - Sao's consumption of viscera and connection with motherhood and childbirth - also link her with the mythology of the vampire (see Figure 4). In the film, Num asks why phi krasue likes to eat baby entrails. Anthropological studies of shamanism and spirit possession reveal that in many cultures menstrual blood, or placenta, are considered unclean, therefore "[m]enstruating, pregnant, and parturient women are believed to be especially vulnerable to the mischievous action of evil spirits" (Karim, 2003, p. 62). In Thai shamanic rituals, menstrual blood is considered "the most dangerous pollutant...harmful to men and sacred objects" (Patamajorn, 2007, p. 179) and "[t]he pollution of blood adheres to the female body and is valued in the negative sense" (p. 180). Anders Poulsen also mentions the prevalence of beliefs that spirits like phi pop, or phi krasue, pose a particular risk to women giving birth because their weakened body often cannot withstand exorcism (2007, pp. 52-53). But for cultural scholars, this connection is both much older and transcultural. 


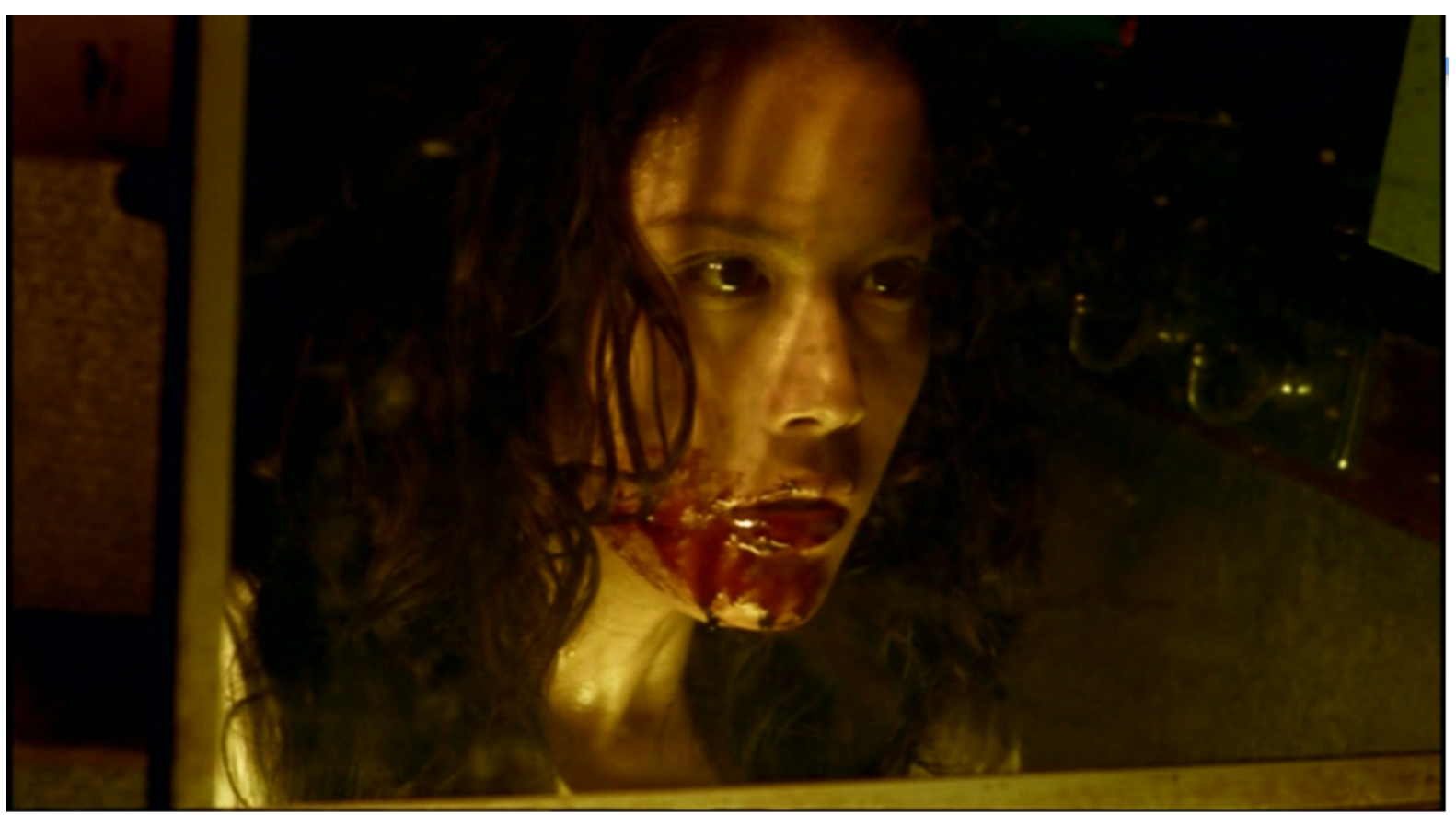

Figure 4. The vampiric side of Sao as "the devourer of children" portrayed here after a feast (Sippapak, Krasue Valentine, 2006)

Vampirologists are familiar with the myth of Lilith, the archetypical female demon and the mother of vampires. Summerian records describe her as a "winged spirit who preyed on pregnant women and infants" (Gaines, 2017, para. 1), and Talmudic references portray her as "a succubus, a demon in female form who had sex with men while the men were sleeping" (para. 12). Lilith has been described as an evil spirit that causes illness and death (para. 16), but while she devours children she is also famous for her uncanny reproductive powers spawning hundreds of demons each day (only to have most of them killed by angels) (para. 20). Creed reads the female vampire through her connection with menstrual blood, motherhood and desire, pointing out that she "releases the blood of another woman" (1993, p. 61), and is capable of giving birth to other vampires through her bite. She also notices that blood "is the first food of the foetus/vampire" (p. 69) equating pregnancy with a vampiric experience. In Krasue Valentine, Sao suffers because of her desire. She is portrayed as a wanton woman engaging in pre-marital sex and an irresponsible mother aborting the baby out of convenience. By refusing to become a mother when still alive, she inadvertently produces a ghost offspring that will eventually orchestrate her demise. The decision to kill her unborn child also turns her into a creature that feeds on children, while her reincarnation as a nurse brings her into proximity of women in labour. Sao is thus simultaneously a mother, an antimother, and a potential devourer of children. In the final scene of the film we see her trapped by the ghost of her child with whom she is now reunited. Although the film suggests the aborted child was a boy, it appears as a girl in a blood-red uniform - a predatory descendant in her own right. 


\section{Vampire in the city}

Steve Pile describes the modern city as vampiric: "living off the dead labour (as Marx might have it) of its denizens, denizens who are only dimly aware of its vampiric temporalities - even as they themselves are becoming creatures of the night, in the $24 / 7$ city" (2005, p. 129). Like the vampire, the city can wait, its "immortal perspective" leading to "a callous indifference to life" (p. 129) which it consumes for the accumulation of profits. The portrayal of Bangkok in both films certainly fits this description. In $P$, glimpses of the city construct Bangkok as an abject space. Bangkok is introduced as a mess of ugly concrete buildings stripped of paint, pockmarked with rusty metal crates and air conditioner compressors. The spectral, unfinished Sathorn Tower looming over the city serves as a bitter reminder of the 1997 financial crisis. Streets are locked in the never-ending traffic jam and the narrow alleys of the slum are dark, dangerous, and desperate spaces. Low angle shots make the city look more oppressive, revealing the layered structure of elevated motorways, concrete columns of unfinished constructions, and giant aggressive billboards that ask you to buy more. The shimmering colourful Bangkok is stripped of its dazzle and presented in neutral-tone grey and brown. Human life is reduced to accidental shots of poor vendors pushing their humble carts through the streets. Shaky camera movement and fast motion blend images into one consistent blur, inducing a feeling of dizziness that sends a clear message that Bangkok is overwhelming.

In one of the scenes, Dau-phi pop climbs up the unfinished skyscraper left to rot under the unrelenting Bangkok sun. She looks at peace surrounded by crumbling concrete slabs with their steel rods that failed to reinforce them (see Figure 5). This look of serenity is repeated in the final scene when Dau dances in the bar, linking the two places with death and decay. The bar has been stylised to look like a mockery of an ancient temple with a stage set for an unholy ritual. The stage is small and does not offer much space for movement. The dancing girls writhe around their respective poles without much skill or coordination, like animals standing tethered at the market. We have no illusion that they are commodities for sale rather than artists. Dau's room is practically bare and its bathroom is an image of squalor - an open invitation to spirits that live on filth. So are the hotel rooms used for sex with the clients, reduced to bed only, often stained with blood and other bodily fluids.

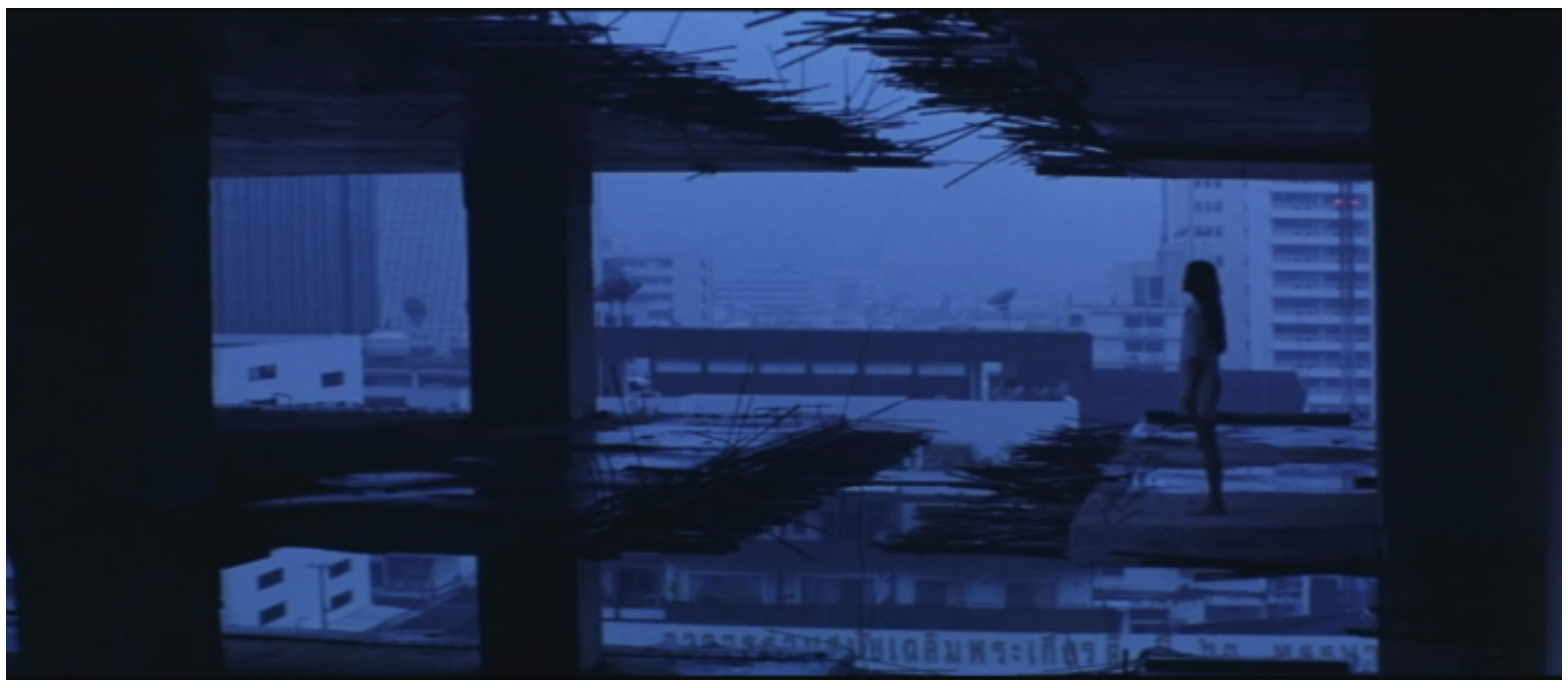

Figure 5. Dau-phi pop meditating among the urban ruins (Spurrier, $P, 2005$ ) 
Although Krasue Valentine features significantly less shots of the city, the few images it leaves us with are equally unflattering. The hospital - once clearly a beautiful building - is now a heap of rotting wood and rusty corrugated iron. Its dumpsters overflow with waste. Surrounded by the skyscrapers of the modern city, the hospital looks like a festering wound that begs to be cauterised (see Figure 6). The house where Sao sleeps belongs in a gothic novel, not only haunted but looking like a ghost itself. Bangkok's love affair with the new has no respect for the old; the new owner quickly dismisses the building as too damaged to be saved. The hospital will most likely be razed to the ground to make room for a shopping mall or a condominium, the most coveted properties in the vampiric city - but the makeover will not liberate it from its ghosts.

The vampiric city feeds off its inhabitants. This is perhaps most visible in these films through the portrayal of the characters that traditionally head Thai socio-cultural hierarchies. Alongside Buddhist monks, the male shaman, mo phi, personifies male patriarchal order. He wields power over spirits and controls them through exorcism rites. The shaman in $P$, however, is a shadow of himself, his supernatural power weakened by drink and poverty, the corruptive effects of living in the city. In Krasue Valentine, (spiritual) authority is represented by two policemen whose uniforms are adorned with magical formulas. Their first confrontation with phi krasue unmasks them as cowardly incompetent fools who run for their lives in fear. The vampire, writes Creed, "is monstrous - and also attractive - precisely because she does threaten to undermine the formal and highly symbolic relations of men and women essential to the continuation of patriarchal society" (1993, p. 61). Just like the two creatures that roam its streets at night, the vampiric Bangkok in the two films seems to be female and share in their abjection.

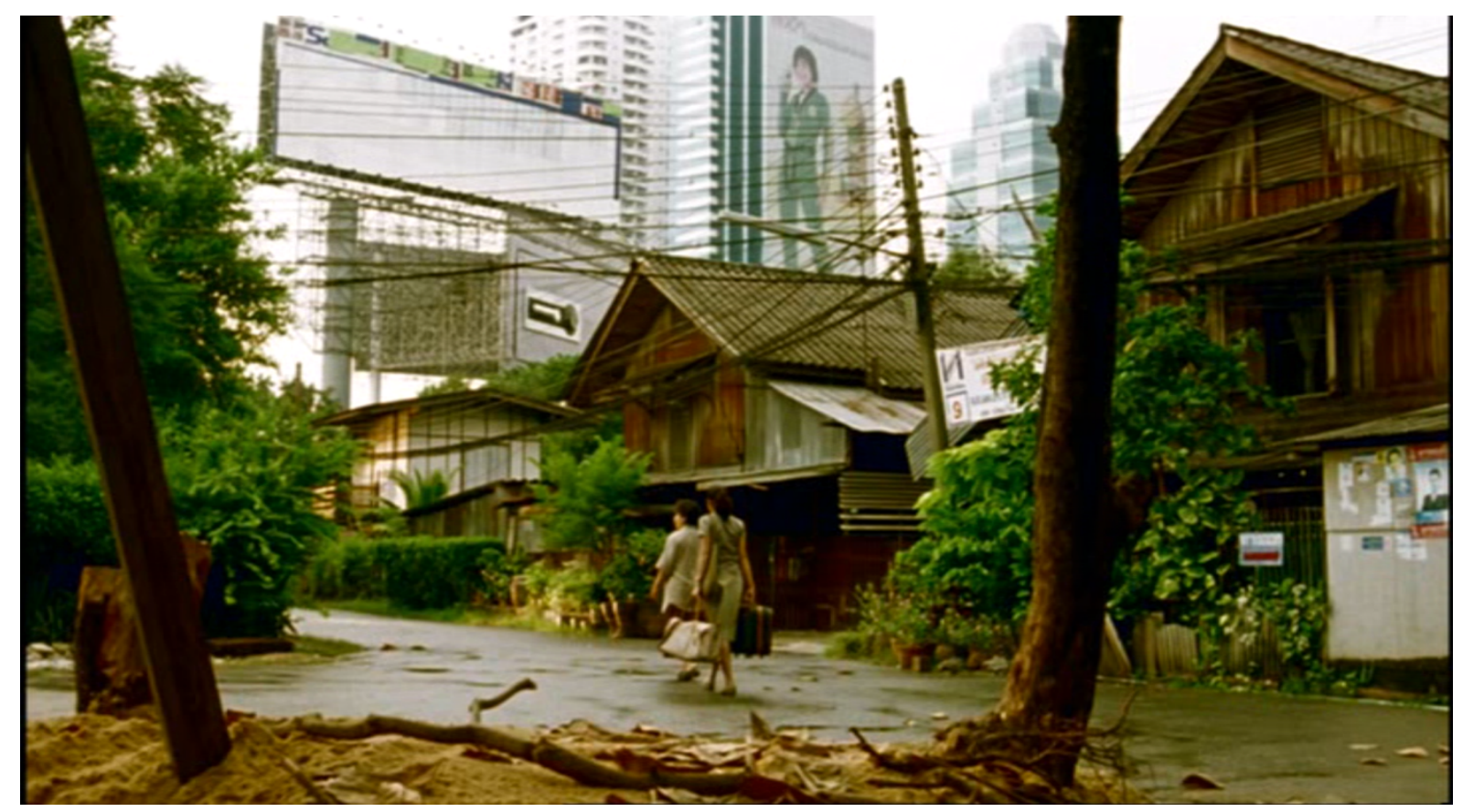

Figure 6. The hospital stands in contrast with the city (Sippapak, Krasue Valentine, 2006) 
Ignoring local beliefs that deny them capacity for change, phi pop and phi krasue seem ready to move to the city, particularly a city like Bangkok, with its lack of urban planning and chaotic infrastructure providing an overabundance of liminal spaces they can inhabit. A slum dwelling, or sex bar, are defined by their temporality, always on the threshold of closure, their existence tolerated but not legal. A derelict property on prime value land is always on the verge of disappearing, snapped up by developers. These liminal spaces highlight Bangkok's deficiencies - overcrowding, congestion, economic inequality, pollution, corruption, poverty, sexual exploitation of the vulnerable - and expose the predatory nature of the city that thrives on blood and money, and offers sex and death in return. Although there is still much to be done, Bangkok has already shown its capacity to act as gender equaliser, with many women who have migrated to the city having begun to exercise more control over their lives. Seizing an opportunity to gain financial independence, city women stand a better chance to resist the patriarchal order. While the most obvious path to improving female agency and inspiring social change in the aggressively materialistic city seems to be the accumulation of capital and the power that goes with it, the promise of prosperity has also tipped the balance towards alternative forms of spiritualism - from the appearance of popular religious sects to a resurgence of urban animism, where the role of women is more prominent. But the labyrinthine structure of the city provides safe space not only for human women; interestingly, urban horror stories insist that almost all the ghosts and monsters inhabiting the city are female.

The two creatures discussed in this paper, phi pop and phi krasue have long been recognised as specifically Thai incarnations of the monstrous feminine. The urban versions of these monsters featured in $P$ and Krasue Valentine differ significantly from their rural ancestors. Phi pop is quick to learn that its voracious appetite is well suited to the dynamics of consumer capitalism, and the liminal spaces inhabited by sex workers can afford it much desired invisibility. Phi krasue, on the other hand, blends in with ghosts, which are seen as more appropriate figures of fear to haunt the city. The representation of these two creatures in the movies discussed also differs from their earlier cinematic portrayals as they acquire more vampiric features borrowed from foreign horror films. In their new forms, the creatures grow prominent fangs and are frequently shown with blood on their faces, even though blood drinking has traditionally never been their primary method of feeding. They are also significantly more sexualised beings than those known from local folklore. While films such as $P$ and Krasue Valentine, which repatriate animistic spirits/monsters to the city, are extremely rare in contemporary Thai horror, it is worth noticing that the depictions of ghosts in the urban setting share this vampiric dimension - as spirits become more corporeal and more bloodthirsty, ghost stories give way to body horror. Thai horror films have always been constructed around local figures of fear representing a massive collection of creatures known collectively as phi, whose fluid identities encompass those of nature spirits, ghosts, demons, gods, and monsters. But the ongoing urbanization of the country and the dizzying speed with which Bangkok has transformed itself into a cutthroat neoliberal metropolis continues to bring these creatures closer to vampires. 


\section{References}

Ainslie, M. (2014). The supernatural and post-war cinema. Horror Studies, 5(2), 157-169.

Baumann, B. (2016). The Khmer witch project: Demonizing the Khmer by Khmerizing a demon. In P. J. Bräunlein \& A. Lauser (Eds.), Ghost movies in Southeast Asia and beyond (pp. 141-183). Leiden: Brill.

Baumann, B. (2014). From filth ghost to Khmer witch: Phi krasue's changing cinematic construction and its symbolism. Horror Studies, 5(2), 183-196.

Brown, T. (2005). Paul Spurrier talks Thailand, ghosts and P. Screenanarchy. Retrieved from http://screenanarchy.com/2005/04/paul-spurrier-talks-thailand-ghosts-and-p.html

Gaines, J. H. (2017). Lilith: Seductress, heroine or murderer? Retrieved from Bible History Daily: http://www.biblicalarchaeology.org/daily/people-cultures-in-the-bible/people-in-the-bible/lilith/

Halberstam, J. (1995). Skin Shows: Gothic Horror and the Technology of Monsters. Durham, NC: Duke University Press.

Hitchcock, A. (Director). (1960). Psycho [Motion Picture]. United States of America: Shamley Productions.

Hudson, D. (2010). Modernity as crisis: Goeng si and vampires in Hong Kong cinema. In J.E. Browning \& C.J. Picart (Eds.), Draculas, vampires, and other undead forms: Essays on gender, race, and culture (pp. 203-234). Lanham, MD: The Scarecrow Press.

Irwin, A. J. (1907). Some Siamese ghost-lore and demonology. Journal of the Siam Society, 4(2), 1946.

Retrieved from

http://www.siameseheritage.org/jsspdf/1904/JSS_004_2c_Irwin_SomeSiameseGhostLoreAndDemonology.pdf

Karim, A. (2003). Shamanism in Bangladesh. In C. Chilson \& P. Knecht (Eds.), Shamans in Asia (pp. 51-85). London: Routledge.

Kirsch, T. A. (1977). Complexity in the Thai religious system: An interpretation. The Journal of Asian Studies, 36(2), 241-266.

Naowarat, S. (Producer). (1973). Krasue Sao (Ghost of Guts Eater) [Motion Picture]. Thailand: Sri Siam Production.

Ng, A. H. S. (2010). "Death and the maiden": The pontianak as excess in Malay popular culture. In J.E. Browning \& C.J. Picart (Eds.), Draculas, vampires, and other undead forms: Essays on gender, race, and culture (pp. 167-185). Lanham, MD: The Scarecrow Press.

Patamajorn, R. (2007). Spirit mediumship in Thailand: A performance theory approach (Doctoral dissertation, The University of Heidelberg). Retrieved from http://archiv.ub.uniheidelberg.de/volltextserver/8423/1/Dissertation_spirit_mediumship_2008.pdf

Pile, S. (2005). Real cities: Modernity, space and the phantasmagorias of city life: London: Sage.

Pisanthanakun, B. \& Wongpoom, P. (Directors). (2004). Shutter. Thailand: GMM Pictures.

Poulsen, A. (2007). Childbirth and tradition in Northeastern Thailand. Copenhagen: Nias Press.

Rajathon, P. A. (1954). The 'phi.' Journal of the Siam Society, 41(2), 153-178. Retrieved from http://www.siameseheritage.org/jsspdf/1951/JSS_041_2c_PhyaAnumanRajathon_ThePhi.pdf

Sippapak, Y. (Director). (2006). Krasue Valentine (Ghost of Valentine) [Motion Picture]. Thailand: Sahamongkol Film International.

Spurrier, P. (Director) (2005). $P$ [Motion Picture]. Thailand: Creative Films Siam.

Suwanlert, S. (1976a). Phii pob: Spirit possession in rural Thailand. In W.P. Lebra (Ed.), Culture-bound syndromes, ethnopsychiatry, and alternate therapies (pp. 68-87). Honolulu, HI: The University of Hawaii Press.

Suwanlert, S. (1976b). Mental health of phii pob: A phenomenon of spirit possession in Northeast Thailand. Journal of Psychiatric Association of Thailand, 17(1), 21-24. 